\title{
Contextual predictors of AUDIT scores among adult men living in India
}

\author{
Danielle R. Madden ${ }^{1}$, Lata Rathi ${ }^{2}$, Ashley Stewart ${ }^{1}$, and John D. Clapp ${ }^{3}$ \\ ${ }^{1}$ College of Social Work, The Ohio State University, Columbus, OH, United States \\ ${ }^{2}$ Orange City College of Social Work, Nagpur, Maharashtra, India \\ ${ }^{3}$ School of Social Work, University of Southern California, Los Angeles, CA, United States
}

\begin{abstract}
Introduction: Currently, little is known about the prevalence of alcohol use in India. In order to begin to address this knowledge gap, this exploratory study examined contextual aspects of drinking events and the relationship between these factors and high-risk drinking.

Methods: A convenience sample of 198 adult men was recruited from rural areas adjacent to the city of Nagpur. Participants were sampled in two waves. Respondents in both waves completed a nine-item survey that addressed alcohol use, including motivation to drink, where one drinks, and with whom one drinks. Demographic characteristics (e.g., income) were also recorded. Respondents recruited in the second wave $(n=98)$ completed the Alcohol Use Disorders Identification Test (AUDIT). The data were analyzed using Poisson regression models.
\end{abstract}

Results: Of those who completed the AUDIT, 37\% were at high risk for developing an alcohol-use disorder (i.e., received a score of 20 or greater). Participants had higher AUDIT scores (i.e., alcohol-use problems) when they reported typically buying alcohol in a shop. Furthermore, respondents with greater weekly incomes and those who drink with the motivation to get very drunk have higher AUDIT scores.

Conclusions: This study found an alarmingly high rate of alcohol use and alcohol-related issues among respondents. A better understanding of drinking patterns and contextual aspects of drinking events is warranted.

\section{Introduction}

India is one of the largest developing countries in the world; however, little is known about the effects of alcohol use in developing countries (Neufeld, Peters, Rani, Bonu, \& Brooner, 2005). Alcohol use in India has evolved over the years and is greatly impacted by many cultural shifts. There are emerging economic and health concerns directly related to the consumption of alcohol in India (Benegal, 2005; Gajalaskshmi \& Peto, 2009; Mohindra, Narayana, Anushreedha, \& Haddad, 2011). For instance, the increase in alcohol use in recent years has greatly impacted the spread of HIV and sexually transmitted infections (Pandey et al., 2012; Sharma, Tripathi, \& Pelto, 2010).

In India there are many consumption trends that are impacted by one's geographic location, which leads us to understand a great deal of variance. Population-level surveys have found that approximately $20 \%$ of adult Indian men regularly consume alcohol (Basu, Ghosh, Patra, \& Subodh, 2015). Nonetheless, other surveys have found great variability in regional prevalence (from $7 \%$ to $75 \%$ ) due to regional policy, population density, and tribal affiliation (Benegal, 2005). In some areas, the initiation of alcohol use is as early as 12 years old (Chaturvedi \& Mahanta, 2004).

It is probably that regional variations in drinking are rooted in contextual differences from region to region. As such, examinations of drinking behavior as it occurs contextually (i.e., location, social context) might be useful to better understand alcohol consumption in India. Little research has addressed the contexts in which Indian citizens drink. While alcohol is potentially only used by half of the population, it is especially prevalent in low-income and rural areas (Neufeld et al., 2005). Those who consume are more likely to do so heavily (Mohindra et al., 2011; Ray, 2004). In past research focusing on the context of drinking among those residing in India, drinkers preferred to drink outside their homes (Ghosh, Samanta, \& Mukherjee, 2012) and at a retail wine store/liquor shop (Girish, Kavita, Gururaj, \& Benegal, 2010). Indian men who preferred to consume alcohol in private were likely alcohol-dependent

Correspondence: Danielle Madden, College of Social Work, 125 Stillman Hall, 1947 College Road, Columbus, OH, 43210, USA. Telephone: 614-292-5572, Fax: 614-292-6940, E-mail: Madden.208@osu.edu

Financial support: no funding to report

Keywords: drinking context, alcohol use, India, AUDIT, survey 
(71.4\%) as determined by Alcohol Use Disorders Identification Test (AUDIT) scores (Ghosh et al., 2012)

Due to the dearth of research available on alcohol-use behaviors of those in developing countries, it is critically important that we assess the contexts in which drinking occurs. A more thorough understanding of the contextual aspects of drinking can lead to the implementation of effective prevention for the overuse of alcohol. To that end, this study addresses the relationship between high-risk drinking and individual characteristics (i.e., age, drinking intentions, earnings) and contextual aspects of typical drinking events (i.e., location, whether people are present).

\section{Methods}

Sample. One hundred and ninety-eight male participants were recruited by accidental sampling in India. Given the exploratory nature of the study and the limited resources available to collect this data in India, a larger sample is not utilized. Participants were recruited during two sampling waves. The first wave was completed in 2014 and included 100 participants. In 2015, an additional 98 participants were recruited during a second sampling wave. All data for both waves were collected from various rural parts near to the city of Nagpur. Volunteer researchers visited houses in the Nagpur District to recruit and interview participants. Only individuals who regularly drank alcohol were eligible to participate. Data from both sampling waves were utilized for descriptives; however, only the second sampling wave $(n=98)$ informed the regression analysis.

Design and Measures. This is an exploratory study that begins to address the contextual aspects of drinking events among Indian men. Participants were asked to complete a short survey about alcohol use. The questions were derived from past research on the contexts of drinking (Clapp, Min, Shillington, Johnson, \& Voas, 2003). In addition to demographic information, the questionnaire included items aimed to measure drinking frequency and behavioral aspects of drinking (where they drink, with whom they drink, and when they drink). Participants also recorded the amount typically spent on alcohol and their drinking intentions (whether they consume alcohol to "feel it"). All 198 participants completed this short survey. Only participants who were recruited during the second wave ( $n$ = 98) completed the AUDIT. The AUDIT was created by the World Health Organization and a brief version was utilized in this study (Babor, Higgins-Biddle, Saunders, \& Monteiro, 2001). The survey includes 10 questions. According to Reinert and Allen (2007), the AUDIT has established internal consistency and reliability and has been studied extensively. It is used to identify harmful patterns of alcohol consumption. All 10 items are summed to create an AUDIT score; scoring instructions can be found elsewhere (Babor et al., 2001). A score of 8 or greater designates the possibility of an alcohol-use disorder. A score of 8-15 indicates that the respondent is displaying hazardous alcohol use, and a score of 16-19 indicates harmful use. Scores of 20 or more are indicative of dependence.
Analyses. Our data were analyzed using generalized Poisson regression models to estimate the association between one's overall AUDIT score and dependent individual and contextual variables. Poisson regression is often utilized for modeling count data and similar methods have been utilized to assess AUDIT data in past research (Reisdorfer, Buchele, Pires, \& Boing, 2012; Toumbourou et al., 2014). Although a sample size of only 98 participants is potentially problematic due to the possibility of under- or over-dispersion, generalized models are an appropriate method with this type of count data (Harris, Yang, \& Hardin, 2012). Individual-level variables included age, rupees earned per week, and typical drinking intentions (e.g., "I drink to feel drunk"). Contextual variables included where one buys alcohol (e.g., hotel/ bar, shop) and where alcohol is typically consumed (e.g., at a home, in a public place). These variables were all measured categorically. The AUDIT score was measured on a continuous scale with scores that could range from 0 to 40. Bivariate analysis was used to explore relationships between all variables, and only those with significant findings were included in the regression model. Additionally, variables were selected for inclusion on the basis of significant findings in past research. We set our alpha-level for significance testing at $p<.05$. All analyses were conducted using SPSS 22.

\section{Results}

A total of 198 male participants completed the survey, and a subset of 98 participants completed the AUDIT. Table 1 provides descriptive information for the entire sample. The majority of participants were between 18 and 30 years of age (49\%). Approximately, one fourth of participants had a weekly income greater than 2000 rupees (approximately equivalent to \$29.67 USD or €26.77 Euro); however, 17\% of participants earned only between 300 rupees $(\$ 4.45$ USD/€4.02 Euro) and 1000 rupees (\$14.83 USD/€13.39 Euro) a week. On average, about $67 \%$ of respondents spent more than 100 rupees per week on alcohol. The majority of participants bought alcohol at a shop (90\%) and consumed alcohol in a public place (62\%). Even though most reported drinking in public, 52\% reported that they typically drink alone (i.e., not with friends, family, or coworkers). Most participants drink just a little but not enough to feel it (66\%), but $20 \%$ of the sample reported typically drinking with the intention to feel very drunk.

Table 2 provides descriptive information for the subsample that completed the AUDIT. The frequencies for specific questions are presented in this table. Overall, participants had AUDIT scores that ranged from 4 to 35, with an average score of 16.54 and a standard deviation of 7.11. When risk levels are considered (Babor et al., 2001), $8 \%$ of the sample were classified as low-risk (score of 0-7), $42 \%$ were classified as displaying risky or hazardous use (score of $8-15$ ), 13\% displayed harmful use (score of 1619), and 37\% were at high risk for developing an alcoholuse disorder (score of 20 or greater). All respondents at high risk were also indicating potential dependence. 
Table 1

Descriptive statistics for individual and contextual variables $(N=198)$

\begin{tabular}{lc}
\hline Variable & \% \\
\hline Age \\
18 to 30 & 49.0 \\
31 to 40 & 30.3 \\
$\quad>41$ & 20.7 \\
Weekly Earnings (Rupees) & \\
$\quad 300$ to 1000 & 16.7 \\
1001 to 1500 & 20.2 \\
1501 to 2000 & 39.9 \\
$\quad$ 2000 & 23.2 \\
Drinking Motivation & \\
$\quad$ Drink just a little but not enough to feel it & 66.5 \\
$\quad$ Drink enough to feel good & 13.2 \\
Drink enough to feel very drunk & 20.3 \\
Typical Amount Spent on Drinking (Rupees) & \\
30 to100 & 33 \\
101 to 300 & 50.8 \\
$\quad>301$ & 16.2 \\
Typical Drinking Location & \\
Public place & 61.6 \\
My home or someone else's home & 38.4 \\
Whom Drink With & \\
Alone & 51.8 \\
Friends/co-workers & 48.2 \\
Location Alcohol is Purchased & \\
Shop & 89.4 \\
Hotel/bar & 10.6 \\
\hline
\end{tabular}

\section{Table 2}

Descriptive statistics for the AUDIT $(n=98)$

Variable

Q1. How often do you have a drink containing alcohol?

Monthly or less

$\%$

$2-4$ times a month

5.1

2-3 times a week

33.3

4 or more times a week

16.2

45.5

Q2. How many drinks containing alcohol do you have on a typical day when you are drinking?

$\begin{array}{lc}1 \text { or } 2 & 4 \\ 3 \text { or } 4 & 45.5 \\ 5 \text { or } 6 & 36.4 \\ 7 \text { to } 9 & 14.1\end{array}$

Q3. How often do you have six or more drinks on one occasion?

Never

22.4

Less than monthly 29.6

Monthly 27.6

Weekly $\quad 4.1$

Daily or almost daily 16.3

Q4. How often during the last year have you found that you were not able to stop drinking once you started?
Never

Less than monthly $\quad 20.4$

Monthly 21.4

Weekly $\quad 1$

Daily or almost daily 14.3 


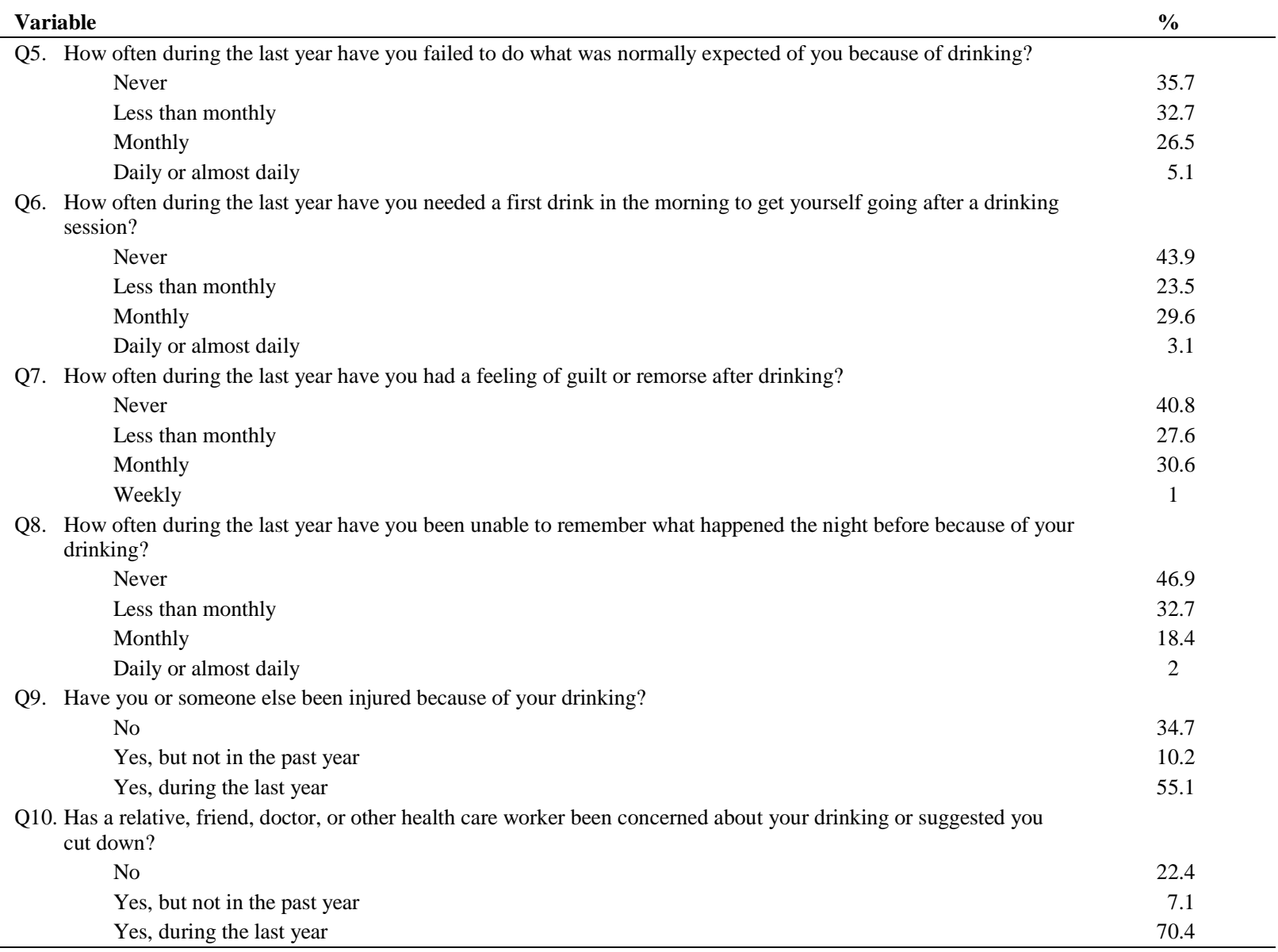

Table 3 presents the results of the Poisson regression analysis. The Poisson regression models the log of the AUDIT count score as a function of the predictor variables. These data are slightly under-dispersed (with a Pearson dispersion statistic of 0.94); nonetheless, a generalized Poisson regression model has been shown to be suitable for under-dispersed data when compared to other Poisson models (Harris et al., 2012). When other variables are held constant, the incident rate for those who earn only 300 to 1000 rupees per week is 0.8 times the incident rate for those who earn more than 2000 rupees per week (95\% confidence interval [CI] $[-0.46,-0.01])$. Essentially, those who earn less per week have lower AUDIT scores. Furthermore, the incident ratio for participants who buy alcohol in a hotel or bar is 0.83 times the incident rate for those who buy alcohol in a shop (95\% CI $[-0.33,-0.38])$. Respondents who buy alcohol in a shop have higher AUDIT scores. The incident rate for those who drink just a little but not enough to feel it is 0.45 times the incident rate for participants who drink enough to feel very drunk (95\% CI $[-0.92,-0.70])$. Likewise, the incident rate for respondents who drink to feel good is 0.73 times the incident rate for those who drink enough to feel very drunk (95\% CI $[-0.48,-0.16])$. Respondents who drink to feel very drunk have higher AUDIT scores than both those who prefer not to drink enough to feel it or who prefer to drink only enough to feel good.

\section{Discussion}

This exploratory study examined the relationship among drinking behavior and AUDIT scores among men residing near the city of Nagpur in India. The study begins to address the issue of how contexts might relate to heavier drinking among Indian men. To this end we found that income and place of purchase were related to drinking. Past research has illustrated that drinking tends to occur more frequently in low-income rural areas (Neufeld et al., 2005). Our sample only included residents of rural areas near the city of Nagpur who generally reported low weekly incomes. Even though all participants were sampled from low-income areas, we found that respondents who earned slightly higher weekly incomes drank more heavily. Purchasing alcohol in shops was also related to heavier drinking. These findings are likely an indirect indicator of availability. Higher incomes and lower alcohol prices (the likely price difference between shops and hotels) lead to heavier drinking. 
Table 3

Results of the regression model predicting AUDIT scores

\begin{tabular}{|c|c|c|c|c|c|c|}
\hline & \multirow[b]{2}{*}{ B } & \multirow[b]{2}{*}{ Std. Error } & \multicolumn{2}{|c|}{$\begin{array}{l}\text { 95\% Wald Confidence } \\
\text { Interval }\end{array}$} & \multicolumn{2}{|c|}{ Hypothesis Test } \\
\hline & & & Lower & Upper & Wald Chi-Square & Sig. \\
\hline (Intercept) & 3.315 & 0.093 & 3.134 & 3.497 & 1281.556 & 0.001 \\
\hline \multicolumn{7}{|l|}{ Age } \\
\hline $18-30$ & 0.004 & 0.068 & -0.130 & 0.138 & 0.004 & 0.952 \\
\hline $31-40$ & 0.022 & 0.064 & -0.104 & 0.148 & 0.118 & 0.731 \\
\hline$>40$ & Ref. & & & & & \\
\hline \multicolumn{7}{|l|}{ Earnings (Rupees) } \\
\hline $300-1000$ & -0.229 & 0.116 & -0.457 & -0.001 & 3.878 & 0.049 \\
\hline $1001-1500$ & -0.088 & 0.091 & -0.268 & 0.091 & 0.936 & 0.333 \\
\hline $1501-2000$ & -0.123 & 0.077 & -0.274 & 0.028 & 2.561 & 0.109 \\
\hline$>2000$ & Ref. & & & & & \\
\hline \multicolumn{7}{|l|}{ Where Buy } \\
\hline Hotel/Bar & -0.185 & 0.075 & -0.331 & -0.038 & 6.096 & 0.014 \\
\hline Shop & Ref. & & & & & \\
\hline \multicolumn{7}{|l|}{ Intentions } \\
\hline Not enough to feel it & -0.808 & 0.059 & -0.924 & -0.692 & 186.134 & 0.001 \\
\hline To feel good & -0.322 & 0.082 & -0.483 & -0.161 & 15.295 & 0.001 \\
\hline To feel very drunk & Ref. & & & & & \\
\hline \multicolumn{7}{|l|}{ Drinking Location } \\
\hline $\begin{array}{l}\text { Home or someone else's home } \\
\text { In public }\end{array}$ & $\begin{array}{c}-0.029 \\
\text { Ref. }\end{array}$ & 0.058 & -0.142 & 0.084 & 0.248 & 0.618 \\
\hline
\end{tabular}

\begin{tabular}{|c|c|c|c|}
\hline & \multirow[b]{2}{*}{$\operatorname{Exp}(B)$} & \multicolumn{2}{|c|}{$\begin{array}{l}\text { 95\% Wald Confidence } \\
\text { Interval for Exp (B) }\end{array}$} \\
\hline & & Lower & Upper \\
\hline (Intercept) & 27.529 & 22.960 & 33.008 \\
\hline \multicolumn{4}{|l|}{ Age } \\
\hline $18-30$ & 1.004 & 0.878 & 1.148 \\
\hline $31-40$ & 1.022 & 0.901 & 1.159 \\
\hline \multicolumn{4}{|l|}{$>40$} \\
\hline \multicolumn{4}{|l|}{ Earnings (Rupees) } \\
\hline $300-1000$ & 0.795 & 0.633 & 0.999 \\
\hline $1001-1500$ & 0.915 & 0.765 & 1.095 \\
\hline $1501-2000$ & 0.884 & 0.760 & 1.028 \\
\hline \multicolumn{4}{|l|}{$>2000$} \\
\hline \multicolumn{4}{|l|}{ Where Buy } \\
\hline Hotel/Bar & 0.831 & 0.718 & 0.963 \\
\hline \multicolumn{4}{|l|}{ Shop } \\
\hline \multicolumn{4}{|l|}{ Intentions } \\
\hline Not enough to feel it & 0.446 & 0.397 & 0.501 \\
\hline To feel good & 0.725 & 0.617 & 0.852 \\
\hline \multicolumn{4}{|l|}{ To feel very drunk } \\
\hline \multicolumn{4}{|l|}{ Drinking Location } \\
\hline $\begin{array}{l}\text { Home or someone else's home } \\
\text { In public }\end{array}$ & 0.972 & 0.868 & 1.088 \\
\hline
\end{tabular}

Our findings should be viewed with caution. The limitations to the study are numerous. First, the sample is based on those willing to participate in the study. With limited resources we were unable to draw a random sample representative of any population. Second, due to our limited resources (we used volunteer data collectors), only half the sample completed the AUDIT. The sample size is small, and results from statistical models may be impacted by under-dispersion. Finally, because data were collected in the field without incentives, the contextual measures we were able to collect were minimal. The sample was also limited to only men.
These shortcomings should be addressed in future studies. Although limited, our findings do suggest that further inquiry into drinking could be important given the fairly high-risk rates we found. A better understanding of drinking patterns over time coupled with event-level data would be very useful to move this work forward. Given the upward tick in drinking in India, such studies are both warranted and important. As more data become available, prevention programming and policies that support them are also warranted. On the environmental level, programs (e.g., law enforcement, taxation) that target cheap or illicitly manufactured alcoholic beverages may be adapted from other contexts. On the individual level, programs 
implementing a Screening, Brief Intervention, and Referral to Treatment (SBIRT) model might be appropriate.

\section{References}

Babor, T. F., Higgins-Biddle, J. C., Saunders, J. B., \& Monteiro, M. G. (2001). AUDIT. The Alcohol Use Disorders Identification Test: Guidelines for use in primary health care (2 ${ }^{\text {nd }} E d$.) (No. WHO/MSD/ MSB/01.6a). Geneva, Switzerland: World Health Organization.

Basu, D., Ghosh, A., Patra, B., \& Subodh, B. N. (2015). Addiction research in India. In S. Malhotra \& S. Chakrabarti (Eds.), Developments in psychiatry in India (pp. 367-403). New Delhi, India: Springer India.

Benegal, V. (2005). India: Alcohol and public health. Addiction, 100(8), 1051-1056.

Chaturvedi, H. K., \& Mahanta, J. (2004). Sociocultural diversity and substance use pattern in Arunachal Pradesh, India. Drug and Alcohol Dependence, 74(1), 97-104.

Clapp, J. D., Min, J. W., Shillington, A., Johnson, M., \& Voas, R. (2003). Two studies examining environmental predictors of heavy drinking by college students. Prevention Science, 4(2), 99-108.

Gajalakshmi, V., \& Peto, R. (2009). Smoking, drinking and incident tuberculosis in rural India: Population-based case-control study. International Journal of Epidemiology, 38(4), 1018-1025.

Ghosh, S., Samanta, A., \& Mukherjee, S. (2012). Patterns of alcohol consumption among male adults at a slum in Kolkata, India. Journal of Health, Population and Nutrition, 30(1), 73-81.

Girish, N., Kavita, R., Gururaj, G., \& Benegal, V. (2010). Alcohol use and implications for public health: Patterns of use in four communities. Indian Journal of Community Medicine, 35(2), 238-244.

Harris, T., Yang, Z., \& Hardin, J. W. (2012). Modeling underdispersed count data with generalized Poison regression. The Stata Journal, 12(4), 736-747.

Mohindra, K., Narayana, D., Anushreedha, S., \& Haddad, S. (2011). Alcohol use and its consequences in South India: Views from a marginalised tribal population. Drug and Alcohol Dependence, 117(1), 70-73.

Neufeld, K. J., Peters, D. H., Rani, M., Bonu, S., \& Brooner, R. K. (2005). Regular use of alcohol and tobacco in India and its association with age, gender, and poverty. Drug and Alcohol Dependence, 77(3), 283-291.

Pandey, A., Mishra, R. M., Reddy, D. C. S., Thomas, M., Sahu, D., \& Bharadwaj, D. (2012). Alcohol use and STI among men in India: Evidences from a national household survey. Indian Journal of Community Medicine, 37(2), 95-100.

Ray, R. (2004). The extent, pattern and trends of drug abuse in India-National survey. New Delhi, India: Ministry of Social Justice and Empowerment, Government of India and United Nations Office on Drugs and Crime.

Reinert, D. F., \& Allen, J. P. (2007). The Alcohol Use Disorders Identification Test: An update of research findings. Alcoholism: Clinical and Experimental Research, 31(2), 185-199.

Reisdorfer, E., Buchele, F., Pires, R. O., \& Boing, A. F. (2012). Prevalence and associated factors with alcohol use disorders among adults: A population-based study in southern Brazil. Revista Brasileira de Epidemiologia, 15(3), 582-594.

Sharma, H. K., Tripathi, B. M., \& Pelto, P. J. (2010). The evolution of alcohol use in India. AIDS and Behavior, 14(Suppl. 1), S8-S17.

Toumbourou, J. W., Evans-Whipp, T. J., Smith, R., Hemphill, S. A., Herrenkohl, T. I., \& Catalano, R. F. (2014). Adolescent predictors and environmental correlates of young adult alcohol use problems. Addiction, 109(3), 417-424. 